\title{
Polygalacin D induces apoptosis and cell cycle arrest via the PI3K/Akt pathway in non-small cell lung cancer
}

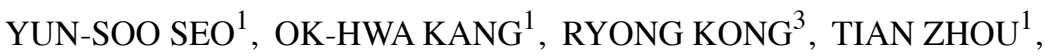 \\ SANG-A KIM ${ }^{1}$, SHIYONG RYU ${ }^{2}$, HAK-RYUL KIM ${ }^{3}$ and DONG-YEUL KWON ${ }^{1}$ \\ ${ }^{1}$ Department of Oriental Pharmacy, College of Pharmacy, Wonkwang Oriental Medicines Research Institute, \\ Wonkwang University, Iksan, Jeonbuk 570-749; ${ }^{2}$ Korea Research Institute of Chemical Technology, \\ Daejeon 305600; ${ }^{3}$ Department of Internal Medicine, Institute of Wonkwang Medical Science, \\ Wonkwang University School of Medicine, Iksan, Jeonbuk 570-749, Republic of Korea
}

Received February 5, 2017; Accepted December 12, 2017

DOI: $10.3892 /$ or.2018.6230

\begin{abstract}
Polygalacin D (PGD) is a bioactive compound isolated from Platycodon grandiflorum (Jacq.) and it has a similar structure to platycodin $\mathrm{D}$, which is a well known anticancer agent. In the present study, we investigated the anti-proliferative effects of PGD using NSCLC cell lines. We evaluated the effects of PGD on proliferation, apoptosis and cell cycle arrest in A549 and H460 cells. PGD significantly induced apoptosis and nuclear condensation in both cell lines. Furthermore, PGD upregulated the cleavage of apoptotic proteins such as caspase-3, -9 and PARP. Additionally, treatment with PGD suppressed the expression of the IAP family of proteins including survivin, cIAP-1 and cIAP-2. Furthermore, PGD induced G0/G1-phase arrest in both cell lines. After treatment with PGD, the expression of TIMP-1, CDK2, cyclin A and cyclin $\mathrm{E}$ was reduced at the protein level. In addition, PGD blocked the PI3K/Akt pathway by inhibiting the phosphorylation of GSK $3 \beta$, Akt and the expression of PI3K. Our results indicated that the anti-proliferative properties of PGD may result from the regulation of the PI3K/Akt pathway, which plays a critical role in cell survival and growth.
\end{abstract}

\section{Introduction}

Lung cancer is the leading cause of cancer-related deaths in both men and women and its incidence has been increasing over the past few decades (1,2). Lung cancer is clinically classified into small-cell lung cancer (SCLC) and non-small cell lung cancer (NSCLC). It is estimated that over $80 \%$ of lung cancer cases are NSCLC (3). NSCLC is further divided into squamous carcinoma, adenocarcinoma and large cell

Correspondence to: Professor Dong-Yeul Kwon, Department of Oriental Pharmacy, College of Pharmacy, Wonkwang Oriental Medicines Research Institute, Wonkwang University, 344-2 Sinyong-dong, Iksan, Jeonbuk 570-749, Republic of Korea E-mail: sssimi@wku.ac.kr

Key words: NSCLC, apoptosis, cell cycle arrest, PI3K/Akt pathway carcinoma based on histological classification. In addition, the classification of NSCLC into subtypes using genetic markers has great importance in relation to the selection of the therapeutic procedure (4). Squamous cell carcinoma is mainly located in the large airways such as the bronchial tree. Large cell carcinoma may occur in any part of the lung and its growth and metastasis are aggressive $(5,6)$. Chemotherapy is the primary treatment option in most cases of lung cancer $(7,8)$. However, treatment with traditional drugs such as cisplatinum is not considered ideal due to its adverse effects and drug resistance (9). Therefore, research has focused on discovering new chemical drugs. Conversely, natural medicine has certain advantages, such as a wide variety of compounds with low toxicity, that could serve as a source of new drugs.

Platycodon grandiflorum (Jacq.) A. DC. (P. grandiflorum) is a well known medicinal plant in East Asian countries. $P$. grandiflorum has been reported to be a plant that contains rich triterpenoid saponins such as platycodin D, D2, D3, deapioplatycodin D, D2, polygalacin D (PGD) and platyconic acid A (10). PGD is classified as a triterpenoid saponin and is one of the main chemical components of P. grandiflorum. PGD has a very similar structure to Platycodin D, a well known anticancer agent (11-14). Based on this relationship, we hypothesized that PGD would also have anticancer effects. However, there are only a few studies concerning the anticancer effects of PGD. In the present study, we investigated the effects of PGD on NSCLC using the adenocarcinoma cell line A549 and the large cell carcinoma NCI-H460 cell line.

\section{Materials and methods}

Reagents. RPMI-1640, fetal bovine serum (FBS), penicillin and streptomycin were purchased from HyClone Laboratories Inc., (Logan, UT, USA). Bovine serum albumin (BSA), 3-(4,5-dimethylthiazol-2-yl)-5-(3-carboxymethoxyphenyl)2-(4-sulfophenyl)-2H-tetrazolium (MTS), 4',6-diamidino -2-phenylindole (DAPI) and dimethyl sulfoxide (DMSO) were purchased from Sigma-Aldrich (St. Louis, MO, USA). TIMP-1 (mouse, monoclonal, sc-365905), Cdk2 (mouse, monoclonal, sc-6248), cyclin A (rabbit, polyclonal, sc-751), cyclin E (rabbit, polyclonal, sc-198), P-GSK3 $\beta$ (mouse, monoclonal, sc-81495), 
GSK3 $\beta$ (mouse, monoclonal, sc-81462), PI3K (rabbit, polyclonal, sc-602) and $\beta$-actin (mouse, monoclonal, sc-47778) were all purchased from Santa Cruz Biotechnology Inc., (Santa Cruz, CA, USA). Cleaved PARP (rabbit, polyclonal, \#9541s), survivin (rabbit, monoclonal, \#2808s), Cdk4 (rabbit, monoclonal, \#12790s), cyclin D (rabbit, monoclonal, \#2978s), p-Akt (rabbit, monoclonal, \#4058s) and Akt (rabbit, polyclonal, \#9272s) were purchased from Cell Signaling Technology (Beverly, MA, USA). Caspase-3 (active, rabbit, polyclonal, ALX-210-807-c100), caspase-9 (active, rabbit, polyclonal, ALX-210-816-c100), cIAP-1 (rat, monoclonal, ALX-803335-c100) and cIAP-2 (rat, monoclonal, ALX-803-341-c100) were purchased from Enzo Life Sciences (Farmingdale, NY, USA) and diluted 1:1,000. Primary antibodies were diluted 1:1,000. Peroxidase-conjugated secondary antibodies (rabbit, monoclonal, sc-2357; mouse, polyclonal, sc-2005; rat, polyclonal sc-2006; dilution 1:2,000) were purchased from Santa Cruz Biotechnology. An enhanced chemiluminescent (ECL) kit was obtained from Amersham Pharmacia Biotech (Buckinghamshire, UK).

Preparation of $P G D$. For the preparation of PGD dried roots, $P$. grandiflorum $(5 \mathrm{~kg})$ underwent extraction three times with methanol at room temperature for seven days. Concentration of the solvent gave a brown syrupy extract $(1.4 \mathrm{~kg})$ which was suspended in water and then partitioned successively with ethyl acetate $(63 \mathrm{~g})$ and $\mathrm{n}$-butanol (130 g). The n-butanol layer was suspended in $\mathrm{H}_{2} \mathrm{O}$ (2 liters) and poured into a Diaion HP-20 column $(\Phi=5.0 \times 100 \mathrm{~cm}$; Mitsubishi Chemicals Corp., Tokyo, Japan), which was stabilized with $\mathrm{H}_{2} \mathrm{O}$. The column was washed with $\mathrm{H}_{2} \mathrm{O}$ (2 liters) and then eluted with $\mathrm{MeOH}$ (5 liters). Polygalacin D2 (PD2) was prepared from the extract of $P$. grandiflorum for experimental procedures using our method (15).

Cell culture and proliferation assay. Human lung cancer cells NCI-A549 and H460 were obtained from the Korean Cell Line Bank (Seoul, Korea) and grown in RPMI-1640 containing $10 \% \mathrm{FBS}, 100 \mathrm{U} / \mathrm{ml}$ penicillin and $100 \mu \mathrm{g} / \mathrm{ml}$ streptomycin. BEAS-2B, a human bronchial epithelial cell line, was purchased from the American Type Culture Collection (CRL-9609; ATCC, Manassas, VA, USA) and maintained in bronchial epithelial cell basal medium (BEBM) containing $1 \%$ penicillin/streptomycin. The cell lines were maintained in a humidified incubator, with an atmosphere of $5 \% \mathrm{CO}_{2}$ at $37^{\circ} \mathrm{C}$. The effect of PGD on cell proliferation was determined using an MTS assay. The cells (2x10\%3ell) were seeded in 96-well culture plates and incubated for $24 \mathrm{~h}$. Various concentrations $(0-40 \mu \mathrm{M})$ of PGD were added and the cells were incubated for $48 \mathrm{~h}$. The optical density (OD) of each culture well was assessed at $490 \mathrm{~nm}$ using a microplate reader (Titertek Multiskan; Flow Laboratories, North Ryde, NSW, Australia). Cell proliferation was calculated using the following formula: (mean absorbance value of treated cells/mean absorbance value of untreated cells) x 100 .

DAPI staining. Cell nuclear morphology was assessed by fluorescence microscopy following DAPI staining. A549 and H460 cells were treated with PGD for $48 \mathrm{~h}$. The cells were washed with phosphate-buffered saline (PBS), fixed with ice

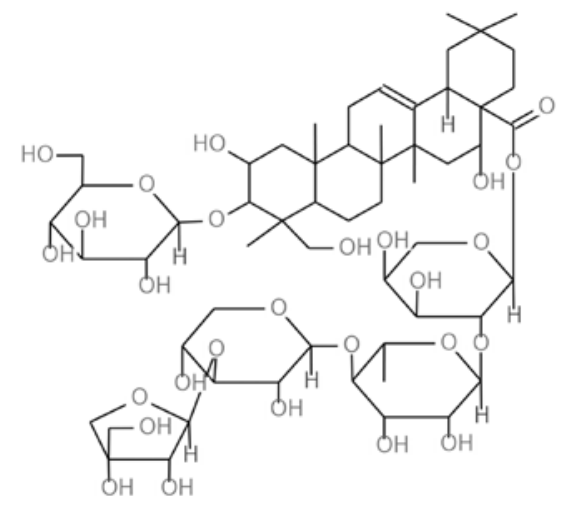

Figure 1. Structure of PGD.

cold $70 \%$ ethanol, stained with DAPI and incubated for 5 min at $37^{\circ} \mathrm{C}$, in the dark. The cells were then washed with PBS and visualized using a fluorescence microscope (Carl Zeiss AG, Oberkochen, Germany).

Detection of apoptosis. The degree of apoptosis was assessed using Muse cell analyzer (EMD Millipore, Billerica, MA, USA) according to the manufacturer's instructions. A549 and $\mathrm{H} 460$ cells were seeded in 6 -well plates $\left(10^{5}\right.$ cells/well $)$ and treated with PGD $(0,10,20$ and $40 \mu \mathrm{M})$ for $48 \mathrm{~h}$. The harvested cells were washed with $1 \mathrm{ml}$ of PBS, resuspended in $150 \mu \mathrm{l}$ FBS free media and $150 \mu \mathrm{l}$ of the Muse ${ }^{\mathrm{TM}}$ Annexin V Dead Cell kit (EMD Millipore) was added. Then, the cells were incubated at room temperature (RT) for $20 \mathrm{~min}$ in the dark. The samples were assessed with the Muse cell analyzer (EMD Millipore).

Cell cycle analysis. A549 and H460 cells were seeded in 6 -well plates $\left(10^{5}\right.$ cells/well) and treated with PGD $(0,10,20$ and $40 \mu \mathrm{M}$ ) for $48 \mathrm{~h}$. The harvested cells were washed with $1 \mathrm{ml}$ PBS and fixed with ice-cold $70 \% \mathrm{EtOH}$ over $3 \mathrm{~h}$. After fixation, the cells were washed with PBS and suspended in $200 \mu \mathrm{l}$ PBS. Muse ${ }^{\mathrm{TM}}$ Cell cycle reagent $(200 \mu 1$; EMD Millipore) was then added and the cells were incubated at RT for $30 \mathrm{~min}$ in the dark. The samples were assessed with the Muse cell analyzer (Merck Millipore).

Western blotting. Cell extracts were subjected to SDS gel electrophoresis and then transferred onto a polyvinylidene fluoride membrane (PVDF; EMD Millipore). The membrane was blocked with $5 \%$ skim milk for $1 \mathrm{~h}$ and probed with primary antibodies. After a series of washes, the membrane was further incubated with a secondary antibody conjugated with horseradish peroxidase (HRP). The proteins were then supplemented with ECL prime western blotting detection reagents (GE Healthcare Life Sciences, Little Chalfont, UK). The bands were evaluated using the ImageQuant LAS 4000 mini biomolecular imager (GE Healthcare Life Sciences).

Statistical analysis. The statistical analysis was performed using one-way analysis of variance (ANOVA), followed by Scheffe's test for multiple comparisons. Data are presented as the means \pm standard deviations $(n=5)$. All calculations were performed using SPSS statistics 23 software (SPSS Inc., 

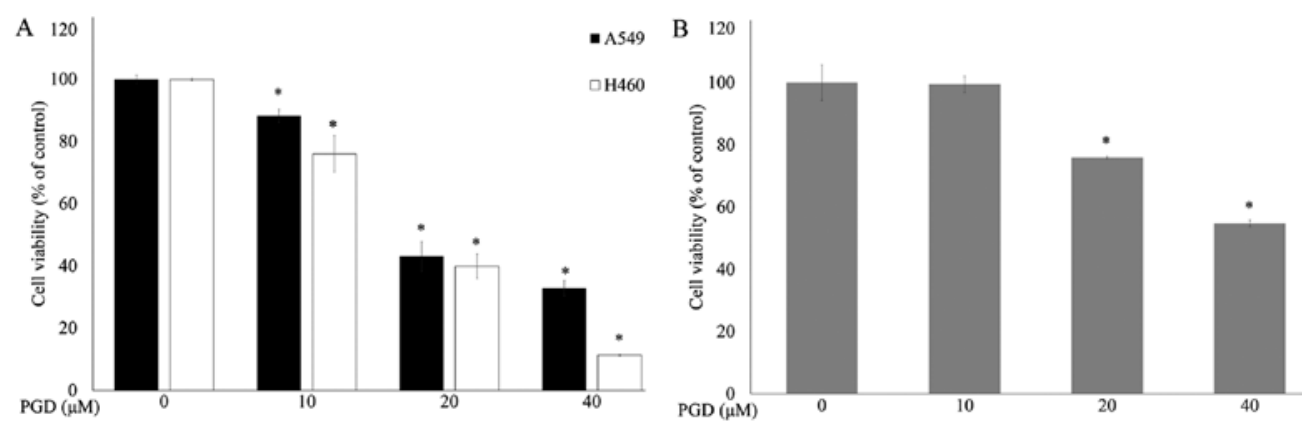

Figure 2. Effect of PGD on cell proliferation in (A) A549 and H460 cancer cell lines and (B) normal airway bronchus cell line BEAS-2B. Cell viability was evaluated with the MTS assay after $48 \mathrm{~h}$ of treatment with various concentrations of PGD. "P $<0.05$ compared to the non-treated group. Significant differences between the treated groups were determined using analysis of variance (ANOVA) followed by Scheffe's test for multiple comparisons. Values represent the means \pm standard deviations of duplicate determinations from three separate experiments.

A549
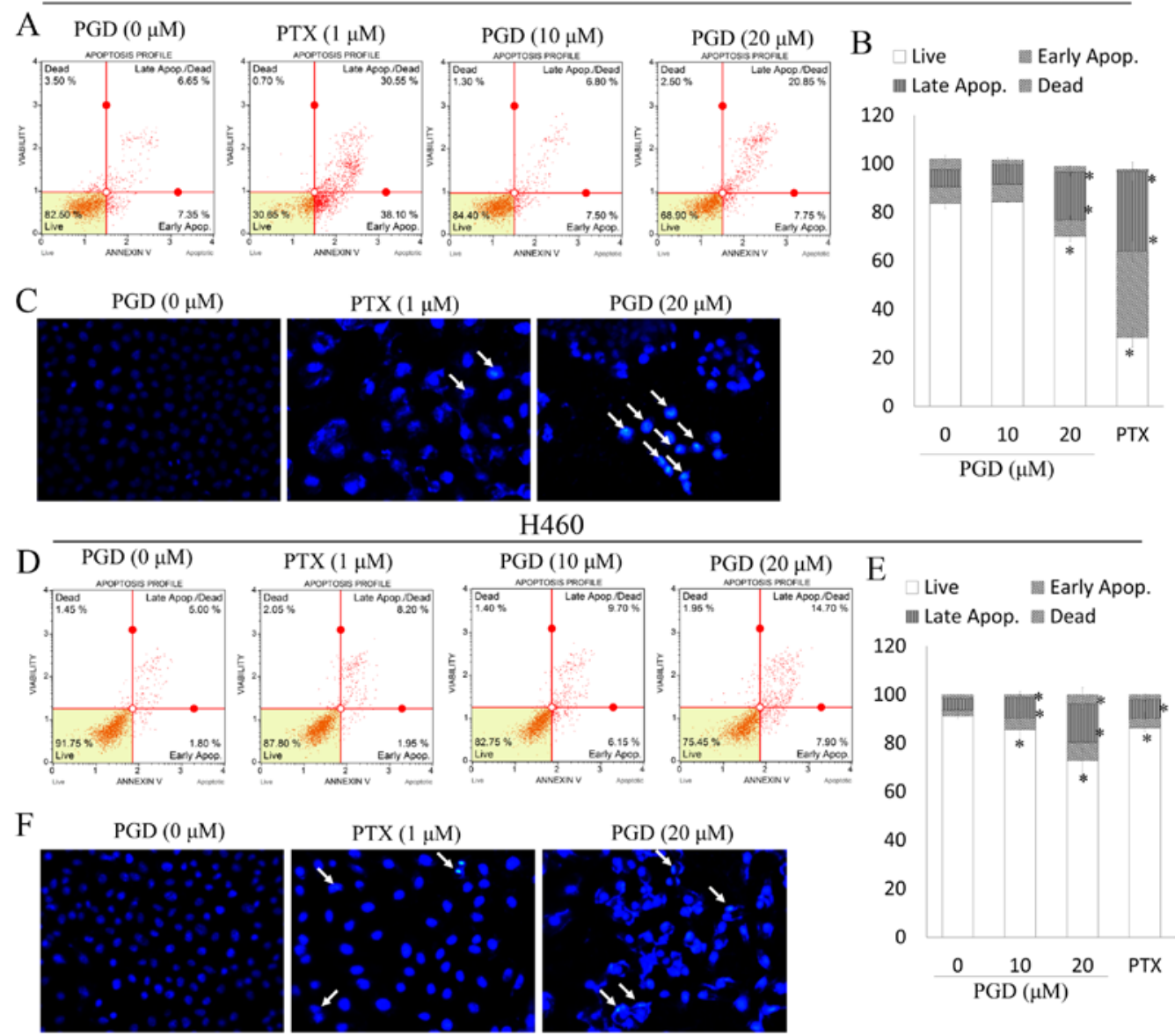

Figure 3. Effect of PGD on apoptosis and nuclear condensation in A549 and H460 cancer cells. (A, B, D and E) The apoptosis rate after $48 \mathrm{~h}$ of treatment with PGD at the indicated concentrations and $1 \mu \mathrm{M}$ PTX (clinical anticancer reagent) was assessed using flow cytometry. (C and F) Nuclear condensation after $48 \mathrm{~h}$ of treatment with PGD was visualized using DAPI staining. Similar results were obtained in three independent experiments and the results of one representative experiment are presented. ${ }^{*} \mathrm{P}<0.05$ compared to the non-treated group. Significant differences between treated groups were determined using Student's t-test. Values represent the means \pm standard errors of duplicate determinations from three separate experiments.

Chicago, IL, USA). $\mathrm{P}<0.05$ was considered to indicate a statistically significant difference.

\section{Results}

$P G D$ inhibits the proliferation of NSCLC cell lines. MTS assays were performed to determine the effects of PGD (Fig. 1) on the proliferation of lung cancer cell lines. Cancer cells were treated with increasing concentrations of PGD. As shown in Fig. 2A, PGD inhibited the growth of the treated cell lines in a dose-dependent manner. The $\mathrm{IC}_{50}$ concentrations of PGD were $26.49 \pm 1.45 \mu \mathrm{M}$ in the A549 cells and $20.52 \pm 0.30 \mu \mathrm{M}$ in the $\mathrm{H} 460$ cells. Treatment with PGD at $40 \mu \mathrm{M}$ reduced cell viability below $70 \%$ in normal airway bronchus cell line (Fig. 2B). Additional experiments were performed using PGD under $20 \mu \mathrm{M}$. 

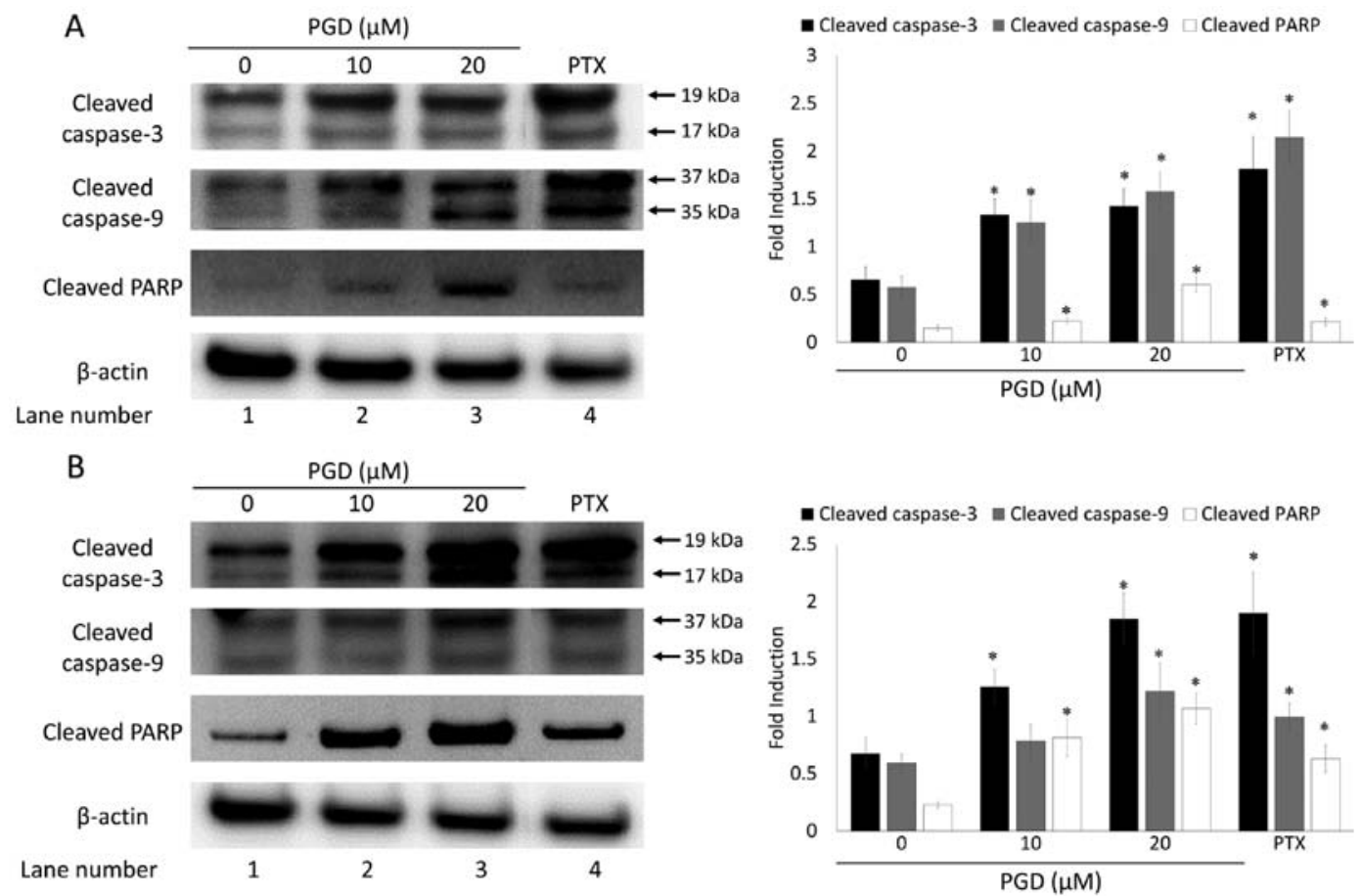

Figure 4. Effects of PGD on the expression of apoptosis-related proteins in (A) A549 and (B) H460 cells. The cells used for western blot analysis were incubated with PGD at the indicated concentrations and $1 \mu \mathrm{M} \mathrm{PTX} \mathrm{(clinical} \mathrm{anticancer} \mathrm{reagent)} \mathrm{for} 48 \mathrm{~h}$. Representative western blots of at least three separate experiments are displayed. " $\mathrm{P}<0.05$ compared to the non-treated group. Significant differences between the treated groups were determined using analysis of variance (ANOVA) followed by Scheffe's test for multiple comparisons. Values represent the means \pm standard deviations of duplicate determinations from three separate experiments.

A

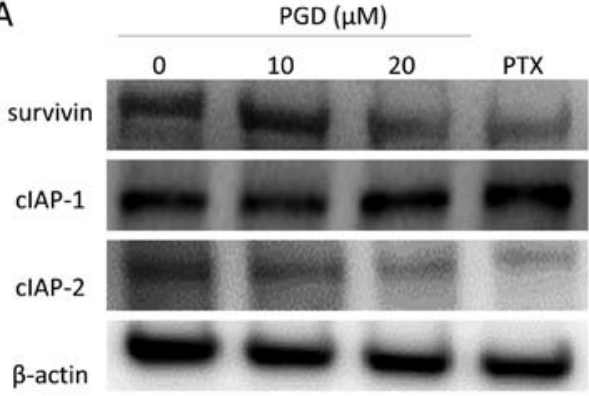

B

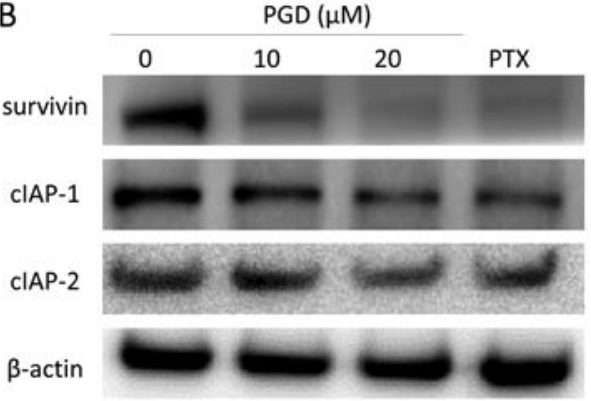

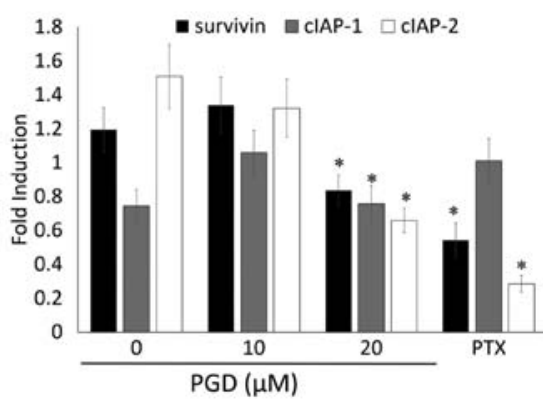

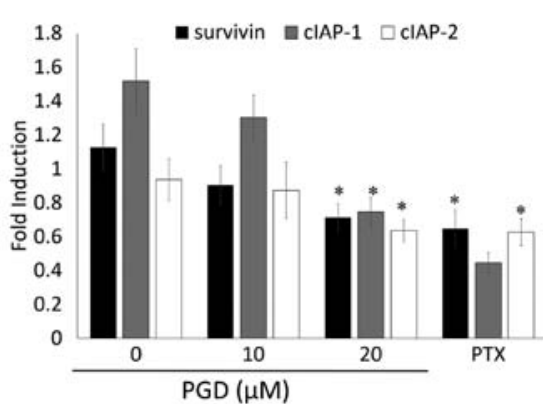

Figure 5. Effects of PGD on the expression of the IAP family of proteins in (A) A549 and (B) H460 cancer cells. The cells used for western blot analysis were incubated with PGD at the indicated concentrations and $1 \mu \mathrm{M}$ PTX (clinical anticancer reagent) for $48 \mathrm{~h}$. Representative western blots of at least three separate experiments are presented. "P $<0.05$ compared to the non-treated group. Significant differences between the treated groups were determined using analysis of variance (ANOVA) followed by Scheffe's test for multiple comparisons. Values represent the means \pm standard deviations of duplicate determinations from three separate experiments.

PGD induces apoptosis of NSCLC cell lines. To determine whether the decreased viability of A549 and $\mathrm{H} 460$ cells occurs as a result of apoptosis, we investigated the apoptotic effects of PGD in NSCLC cell lines. In the present study, pemetrexed
(PTX) was used as a control reagent to assess the apoptotic effects of PGD. PTX has been widely used in the clinical treatment of non-small cell lung cancer. As displayed in Fig. 3C and F, after treatment with PGD, nuclear condensation 

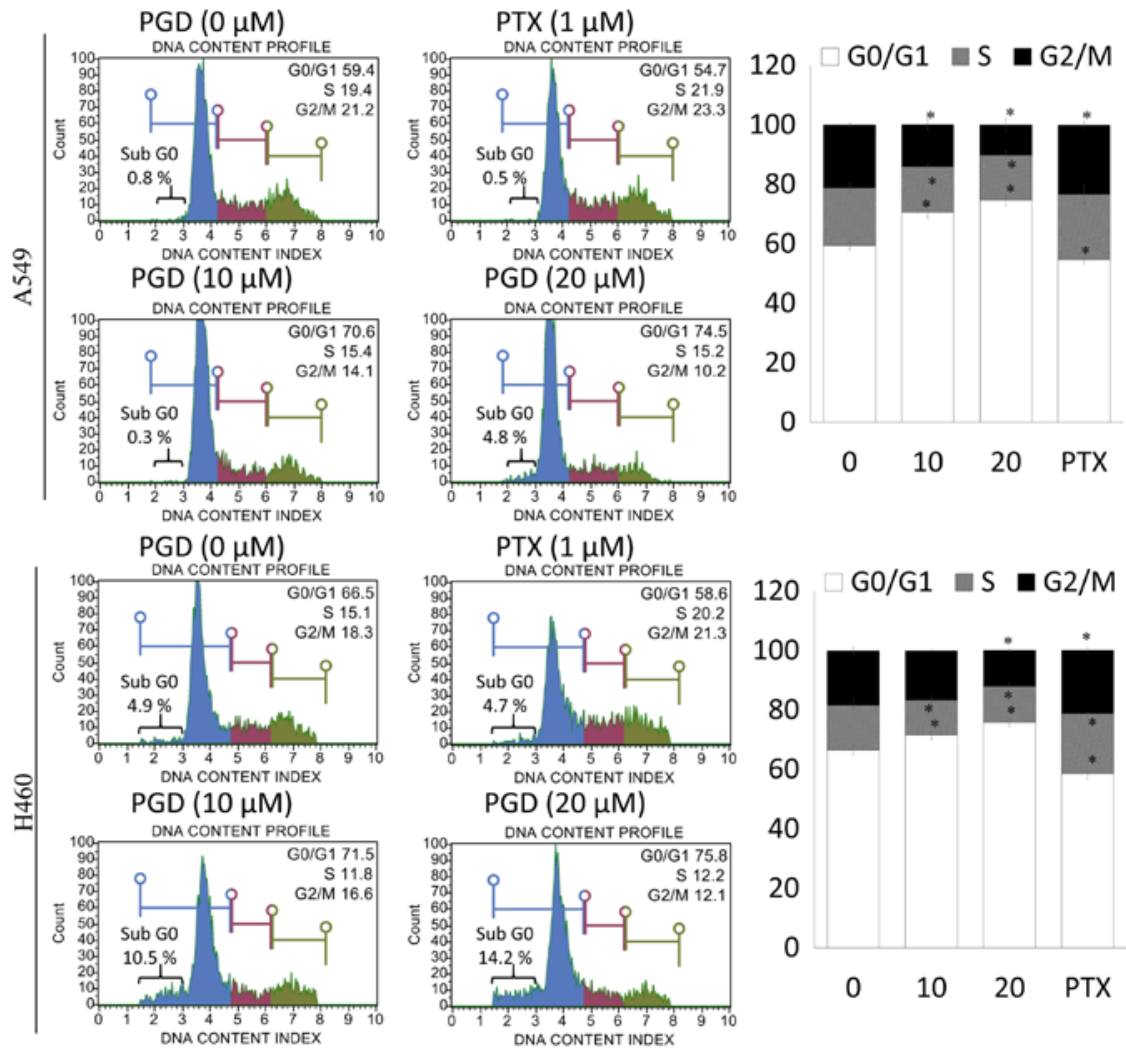

Figure 6. Effects of PGD on cell cycle progression in A549 and H460 cancer cells. The distribution of the cell cycle after $48 \mathrm{~h}$ of treatment with PGD at the indicated concentrations and $1 \mu \mathrm{M}$ PTX (clinical anticancer reagent) was assessed using flow cytometry. ${ }^{*} \mathrm{P}<0.05$ compared to the non-treated group. Significant differences between treated groups were determined using Student's t-test. Values represent the means \pm standard errors of duplicate determinations from three separate experiments.

(white arrows) was observed in A549 and H460 cells. In addition, treatment with PGD increased the proportion of early and late apoptotic cells (Fig. 3A, B, D and E). Collectively, PGD-inhibited proliferation of NSCLC cells was due to cell apoptosis.

PGD regulates the expression of apoptosis-related proteins in NSCLC cells. To elucidate the mechanism by which PGD induced apoptosis, the expression levels of proteins involved in the apoptosis pathway were examined using western blot analysis. The results indicated that treatment with PGD induced the cleavage of caspase- 3 and -9 , as well as PARP in both A549 and H460 cells (in lanes 2 and 3 compared with lane 1; Fig. 4). The expression levels of cleaved caspase-3 and -9 , as well as PARP were markedly increased when compared with those in non-treated cells.

PGD inhibits the IAP pathway in NSCLC cells. To further investigate the effects of PGD on the expression of the IAP family of proteins which play a significant role in intrinsic programmed cell death, NSCLC cells were treated with various concentrations of PGD and then, the expression levels of the IAP family of proteins including survivin, c-IAP-1 and c-IAP-2 were determined using a western blot assay. The expression of survivin, c-IAP-1 and c-IAP-2 was decreased, notably at the highest concentration of PGD, compared with that in non-treated cells. The expression of c-IAP-2 in A549 cells and the expression of survivin and c-IAP-2 in H460 cells was decreased to undetectable levels (Fig. 5). As a result, PGD may exert its apoptotic effects by regulating the apoptotic proteins and the IAP family of proteins.

PGD induces cell cycle arrest in NSCLC cells. To determine whether the effects of PGD on the inhibition of NSCLC cellproliferation were related to cell-cycle arrest, the number of cells in the G0/G1, S and G2/M phases were assessed by flow cytometry. Treatment with PGD inhibited the progression of cell cycle in A549 and H460 cells. As displayed in Fig. 6, the percentage of cells in the G0/G1 phase was significantly increased in PGD-treated A549 and H460 cells compared with non-treated cells. Furthermore, treatment with PGD significantly increased the percentages of the sub G0 phase in both cell lines. In addition, PGD decreased the percentage of cells in the $\mathrm{S}$ and $\mathrm{G} 2 / \mathrm{M}$ phases.

$P G D$ regulates the expression levels of proteins related to cell cycle progression in NSCLC cells. To evaluate the underlying mechanism of the effects of the cell cycle-arrest of PGD, the expression levels of proteins involved in cell cycle progression were determined using western blot analysis. As displayed in Fig. 7, PGD reduced the expression levels of proteins related to the progression of the cell cycle such as TIMP-1, Cdk2, Cdk4, cyclin A, D and $\mathrm{E}$ in both cell lines. In addition, PGD reduced the phosphorylation of GSK3 $\beta$ (Fig. 8), which is also involved in cell cycle progression. These results indicated that the inhibitory effects of PGD on cell growth via cell cycle arrest were induced as a result of a decrease in the expression of proteins related to cell cycle progression. 
A

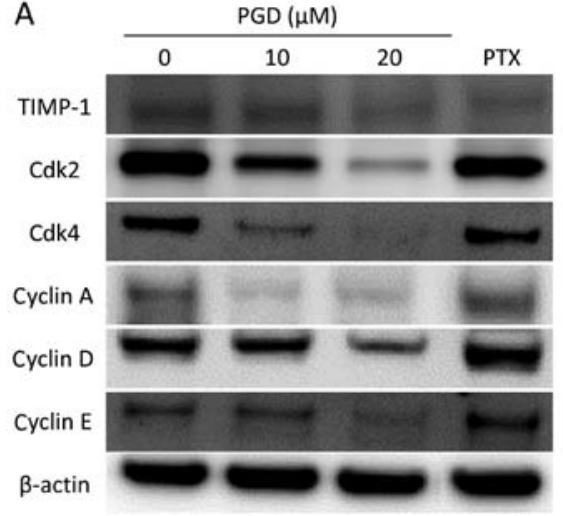

B

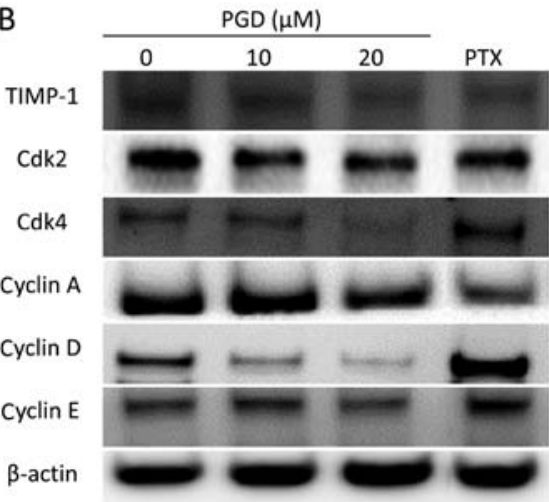

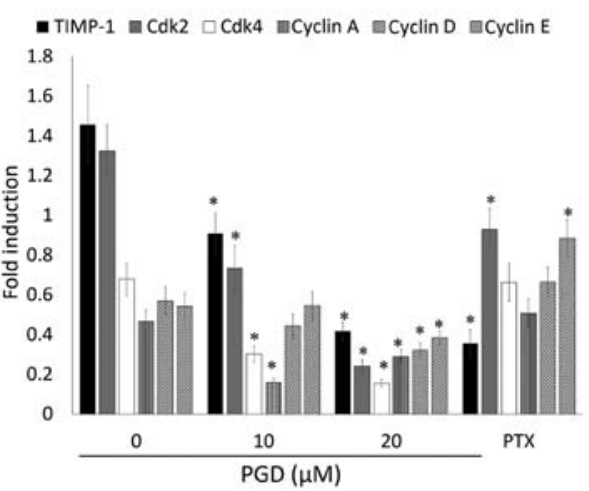

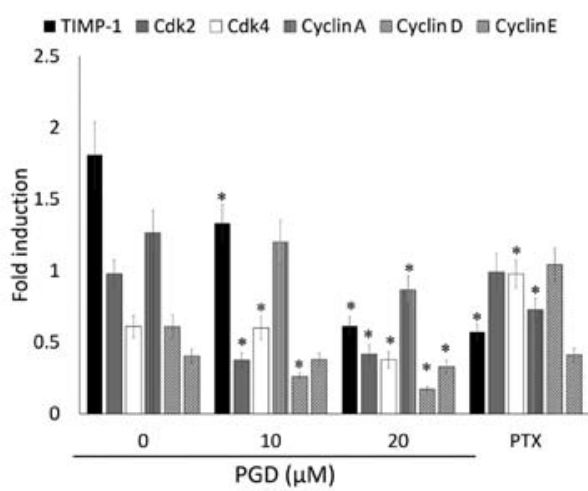

Figure 7. Effects of PGD on the expression of cell cycle progression-related proteins in (A) A549 and (B) H460 cancer cells. The cells used for western blot analysis were incubated with PGD at the indicated concentrations and $1 \mu \mathrm{M}$ PTX (clinical anticancer reagent) for $48 \mathrm{~h}$. Representative western blots of at least three separate experiments are presented. ${ }^{*} \mathrm{P}<0.05$ compared to the non-treated group. Significant differences between the treated groups were determined using analysis of variance (ANOVA) followed by Scheffe's test for multiple comparisons. Values represent the means \pm standard deviations of duplicate determinations from three separate experiments.
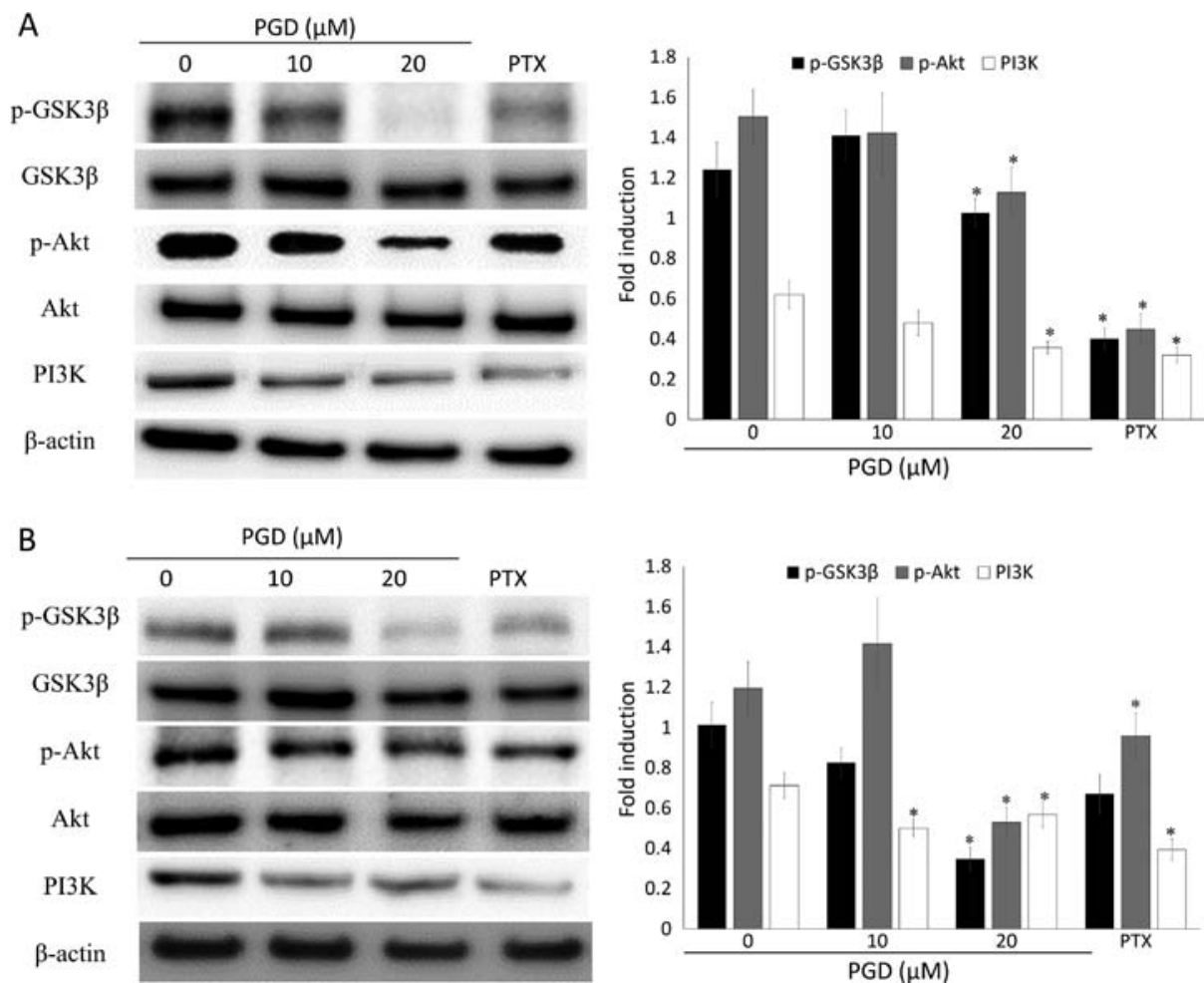

Figure 8. Effects of PGD on the PI3K/Akt pathway in (A) A549 and (B) H460 cancer cells. The cells used for western blot analysis were incubated with PGD at the indicated concentrations and $1 \mu \mathrm{M}$ PTX (clinical anticancer reagent) for $48 \mathrm{~h}$. Representative western blots of at least three separate experiments are presented. ${ }^{\mathrm{P}}<0.05$ compared to the non-treated group. Significant differences between the treated groups were determined using analysis of variance (ANOVA) followed by Scheffe's test for multiple comparisons. Values represent the means \pm standard deviations of duplicate determinations from three separate experiments. 


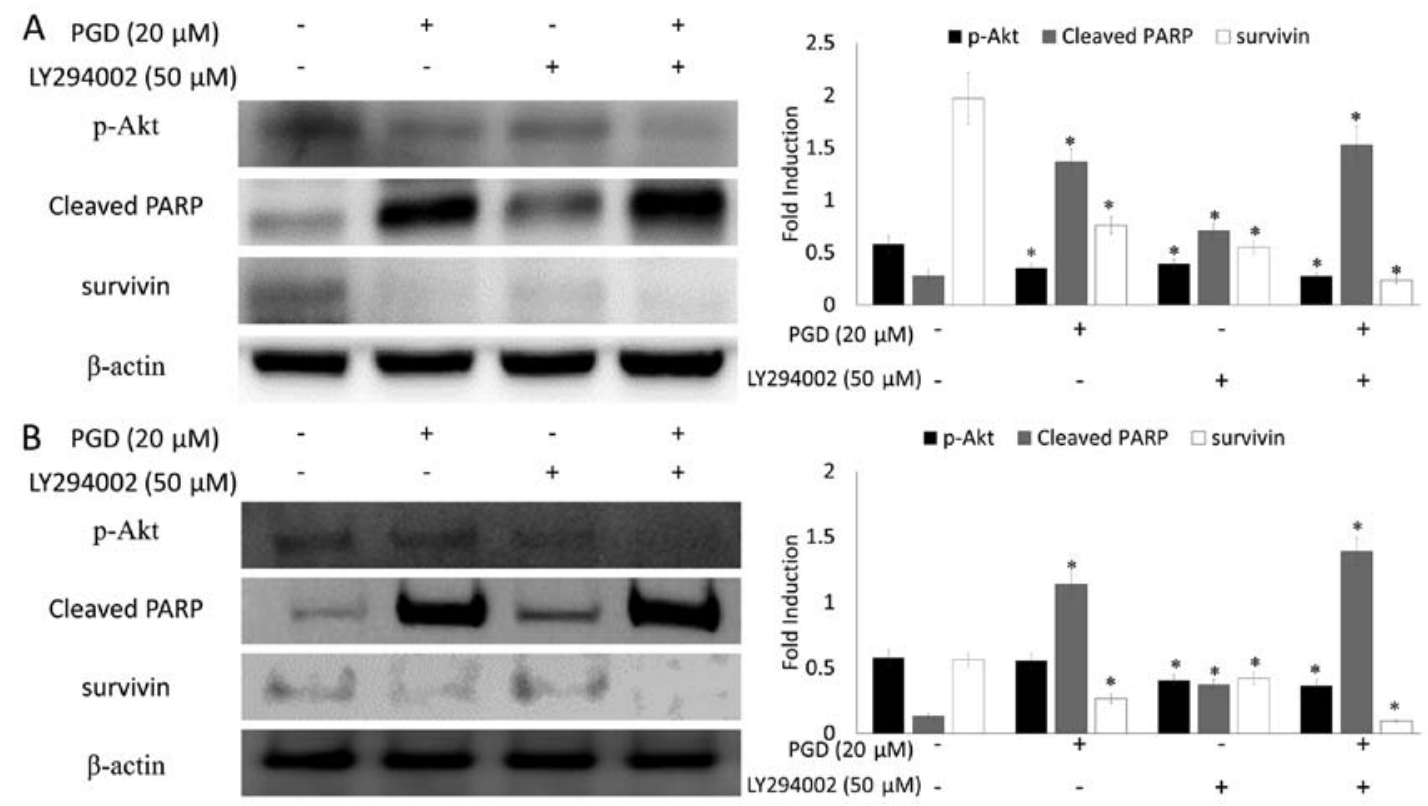

Figure 9. Pharmacological inhibition of Akt on the expression of survivin and cleavage of PARP in PGD-treated (A) A549 and (B) H460 cells. The cells used for western blot analysis were pretreated with or without PI3-kinase inhibitor LY294002, and then further incubated in the presence or absence of $20 \mu \mathrm{M}$ PGD for $48 \mathrm{~h}$. Representative western blots of at least three separate experiments are displayed. ${ }^{*} \mathrm{P}<0.05$ compared to the non-treated group. Significant differences between the treated groups were determined using analysis of variance followed by Scheffe's test for multiple comparisons. Values represent the means \pm standard deviations of duplicate determinations from three separate experiments.

PGD inhibits the PI3K/Akt signaling pathway. Previous research reported that the PI3K/Akt signaling pathway plays a critical role in cell survival. To confirm whether the inhibitory activity of PGD on cell growth was related to the PI3K/Akt signaling pathway, western blot analysis was performed. Treatment with PGD reduced the phosphorylation of Akt, while total Akt remained the same (Fig. 8). In addition, the expression of PI3K was reduced at the highest concentration of PGD compared with the non-treated group. In addition, as displayed in Fig. 9, co-treatment with LY294002 (the inhibitor of PI3K) decreased the expression of survivin and enhanced cleavage of PARP.

\section{Discussion}

In the present study, we examined the potential inhibitory effects of PGD, a triterpenoid saponin contained in P. grandiflorum, which has a similar structure to platycodin $\mathrm{D}$, on cell proliferation in NSCLC cells such as A549 and H460 cell lines. Structure-activity relationships of Platycodon saponins provide important information regarding their bioactive roles (16) and it is expected that they have similar biological activities. However, the anticancer activity of PGD and its mechanisms still remain unclear. As shown in Results, PGD significantly reduced cell viability via the induction of apoptosis and cell cycle arrest. In addition, our finding indicated that PGD inhibited cell survival via regulation of the PI3K/Akt signaling pathway.

Apoptosis is one of the major goals of chemopreventive agents which inhibit the overall growth of cancer cells. Caspases are well-defined proteases related to apoptosis (17). Activation of caspase-3 and -9 induces the cleavage of PARP, eventually resulting in cell apoptosis. IAPs are a group of structurally-related proteins that block apoptosis either by binding and inhibiting caspases or through caspase-independent mechanisms (18). Notably, cIAPs are positive regulators of cell proliferation (19) and expression of cIAPs is associated with advanced disease stage, poor patient prognosis and squamous cell carcinoma (20-22). Survivin is one of the members of the IAP family and is known to play a critical role in cancer cell progression (23). As shown in Fig. 2, PGD significantly reduced cell viability in a dose-dependent manner and revealed $\mathrm{IC}_{50}$ values of $26.49 \pm 1.45 \mu \mathrm{M}$ and $20.52 \pm 0.30 \mu \mathrm{M}$ in A549 and H460 cells, respectively. Furthermore, PGD significantly induced apoptosis, which was accompanied by DNA damage, cleavage of caspase- 3 and -9 , as well as PARP and a decrease in the expression levels of the IAP proteins such as survivin, cIAP-1 and cIAP-2 (Figs. 3-5). These results indicated that the antiproliferative effects of PGD on the NSCLC cell lines were induced by activation of apoptosis-related proteins such as caspase- 3 and -9 as well as PARP and inhibition of the IAP family of proteins such as survivin, cIAP-1 and cIAP-2.

In addition, the inhibitory effects of PGD on cell growth were related to the arrest of cell cycle progression. Our data revealed that treatment with PGD significantly reduced the proportion of cells in the $\mathrm{S}$ and $\mathrm{G} 2 / \mathrm{M}$ phases, followed by an increase in the proportion of cells in the G0/G1 phase. These results were in agreement with the findings of the proliferation assay. Tissue inhibitor of metalloproteinases-1 (TIMP-1) was initially characterized as an endogenous inhibitor of matrix metalloproteinases (MMPs) (24). TIMP-1 is frequently overexpressed in several types of human cancers and promotes cell proliferation (25-27). Cell cycle progression is regulated by cyclins and cyclin-dependent kinases (CDKs). Specifically, cyclin D1 and CDK4 play pivotal roles in the cell cycle transition from the $\mathrm{G} 1$ to the $\mathrm{S}$ phase $(28,29)$. Overexpression of cyclin D1 and CDK4 has been observed in various cancer cells and was strongly associated with the risk of tumor 
progression and metastasis $(30,31)$. CDK2 is a protein kinase essential for the G1/S transition and its activity is limited in the G1/S phase (32). CDK2 forms a complex with cyclin E and this complex leads to the progression of the G1 phase to the $\mathrm{S}$ phase (33). The CDK2/cyclin E complex also induces an increase in cyclin A expression, which facilitates G1 to S-phase transition. Cyclin A binds to CDK2 instead of cyclin $\mathrm{E}$ and this CDK2/cyclin A complex initiates DNA replication, which is required for the progression to the $S$ phase (34). PGD reduced the expression of TIMP-1, CDK2, cyclin A and E and these results were related to the effects of cell cycle arrest of PGD at the G0/G1 phase.

Finally, we investigated the anticipated mechanism that is involved in the aforementioned effects of PGD. The PI3K/Akt pathway is a well-known essential pathway involved in cell proliferation, cycle progression, metastasis, survival and apoptosis and it is one of the most important oncogenic targets in almost all kinds of cancers $(35,36)$. Furthermore, this pathway increases the resistance to DNA damage-induced apoptosis (37). In addition, increased phosphorylation levels of GSK-3 $\beta$, which is a known downstream target, lead to the expression of cyclin D and cMyc, which play a role in the G1/S-phase check point of cell cycle progression and migration $(38,39)$. Therefore, PGD-induced G1 arrest may be attributed to its influence on GSK-3 $\beta$ and upstream Akt and PGD-induced apoptosis may be attributed to the inhibition of Akt phosphorylation.

In conclusion, the anti-proliferative effects of PGD on NSCLC cells may be due to modulation of the PI3K/Akt pathway, which subsequently leads to apoptosis induced by the activation of apoptotic proteins, a decrease in the expression of the IAP family of proteins and growth inhibition induced by cell cycle arrest regulated by CDK2/4, cyclin A, D and E. Based on our findings, PGD exhibits a potential role as a new therapeutic agent for the treatment of NSCLC.

\section{Acknowledgements}

The present study was supported by Wonkwang University in 2017.

\section{References}

1. Chen W, Zheng R, Baade PD, Zhang S, Zeng H, Bray F, Jemal A, Yu XQ and He J: Cancer statistics in China, 2015. CA Cancer J Clin 66: 115-132, 2016.

2. Couraud S, Zalcman G, Milleron B, Morin F and Souquet PJ: Lung cancer in never smokers: a review. Eur J Cancer 48 1299-1311, 2012.

3. Travis WD, Travis LB and Devesa SS: Lung cancer. Cancer 75 (Suppl): 191-202, 1995.

4. Travis WD, Brambilla E, Nicholson AG, Yatabe Y, Austin JHM, Beasley MB, Chirieac LR, Dacic S, Duhig E, Flieder DB, et al; WHO Panel: The 2015 World Health Organization Classification of lung tumors: Impact of genetic, clinical and radiologic advances since the 2004 classification. J Thorac Oncol 10: 12431260,2015

5. Soria JC, Jang SJ, Khuri FR, Hassan K, Liu D, Hong WK and Mao L: Overexpression of cyclin B1 in early-stage non-small cell lung cancer and its clinical implication. Cancer Res 60: 4000-4004, 2000.

6. Yoshida T, Tanaka S, Mogi A, Shitara Y and Kuwano H: The clinical significance of Cyclin B1 and Wee1 expression in nonsmall-cell lung cancer. Ann Oncol 15: 252-256, 2004.

7. Daniel C: Lung cancer, a worrying epidemiological evolution. Rev Infirm 184: 14-16, 2012 (In French).
8. Ball D, Mitchell A, Giroux D and Rami-Porta R; IASLC Staging Committee and Participating Institutions: Effect of tumor size on prognosis in patients treated with radical radiotherapy or chemoradiotherapy for non-small cell lung cancer. An analysis of the staging project database of the International Association for the Study of Lung Cancer. J Thorac Oncol 8: 315-321, 2013.

9. Spira A and Ettinger DS: Multidisciplinary management of lung cancer. N Engl J Med 350: 379-392, 2004.

10. Kim JW, Park SJ, Lim JH, Yang JW, Shin JC, Lee SW, Suh JW and Hwang SB: Triterpenoid saponins isolated from Platycodon grandiflorum inhibit hepatitis $\mathrm{C}$ virus replication. Evid Based Complement Alternat Med 2013: 560417, 2013.

11. Khan M, Maryam A, Zhang H, Mehmood T and Ma T: Killing cancer with platycodin D through multiple mechanisms. J Cell Mol Med 20: 389-402, 2016.

12. Kim MO, Moon DO, Choi YH, Lee JD, Kim ND and Kim GY: Platycodin D induces mitotic arrest in vitro, leading to endoreduplication, inhibition of proliferation and apoptosis in leukemia cells. Int J Cancer 122: 2674-2681, 2008.

13. Zhou R, Lu Z, Liu K, Guo J, Liu J, Zhou Y, Yang J, Mi M and $\mathrm{Xu} \mathrm{H}$ : Platycodin $\mathrm{D}$ induces tumor growth arrest by activating FOXO3a expression in prostate cancer in vitro and in vivo. Curr Cancer Drug Targets 14: 860-871, 2015.

14. Xu C, Sun G, Yuan G, Wang R and Sun X: Effects of platycodin D on proliferation, apoptosis and PI3K/Akt signal pathway of human glioma U251 cells. Molecules 19: 21411-21423, 2014.

15. Choi YH, Yoo DS, Choi CW, Cha MR, Kim YS, Lee HS, Lee KR and Ryu SY: Platyconic acid A, a genuine triterpenoid saponin from the roots of Platycodon grandiflorum. Molecules 13: 2871-2879, 2008.

16. Chun J, Ha IJ and Kim YS: Antiproliferative and apoptotic activities of triterpenoid saponins from the roots of Platycodon grandiflorum and their structure-activity relationships. Planta Med 79: 639-645, 2013.

17. Xie CQ, Zhou P, Zuo J, Li X, Chen Y and Chen JW: Triptolide exerts pro-apoptotic and cell cycle arrest activity on drugresistant human lung cancer A549/Taxol cells via modulation of MAPK and PI3K/Akt signaling pathways. Oncol Lett 12: 3586-3590, 2016.

18. Nachmias B, Ashhab Y and Ben-Yehuda D: The inhibitor of apoptosis protein family (IAPs): An emerging therapeutic target in cancer. Semin Cancer Biol 14: 231-243, 2004.

19. Samuel T, Okada K, Hyer M, Welsh K, Zapata JM and Reed JC: cIAP1 localizes to the nuclear compartment and modulates the cell cycle. Cancer Res 65: 210-218, 2005.

20. Imoto I, Tsuda H, Hirasawa A, Miura M, Sakamoto M, Hirohashi S and Inazawa J: Expression of cIAP1, a target for 11q22 amplification, correlates with resistance of cervical cancers to radiotherapy. Cancer Res 62: 4860-4866, 2002.

21. Tanimoto T, Tsuda H, Imazeki N, Ohno Y, Imoto I, Inazawa J and Matsubara O: Nuclear expression of cIAP-1, an apoptosis inhibiting protein, predicts lymph node metastasis and poor patient prognosis in head and neck squamous cell carcinomas. Cancer Lett 224: 141-151, 2005.

22. Che X, Yang D, Zong H, Wang J, Li X, Chen F, Chen X and Song X: Nuclear cIAP1 overexpression is a tumor stage- and grade-independent predictor of poor prognosis in human bladder cancer patients. Urol Oncol 30: 450-456, 2012.

23. Kishi H, Igawa M, Kikuno N, Yoshino T, Urakami S and Shiina $\mathrm{H}$ : Expression of the survivin gene in prostate cancer: Correlation with clinicopathological characteristics, proliferative activity and apoptosis. J Urol 171: 1855-1860, 2004.

24. Docherty AJ, Lyons A, Smith BJ, Wright EM, Stephens PE, Harris TJ, Murphy G and Reynolds JJ: Sequence of human tissue inhibitor of metalloproteinases and its identity to erythroidpotentiating activity. Nature 318: 66-69, 1985.

25. Gouyer V, Conti M, Devos P, Zerimech F, Copin MC, Créme E, Wurtz A, Porte H and Huet G: Tissue inhibitor of metalloproteinase 1 is an independent predictor of prognosis in patients with non small cell lung carcinoma who undergo resection with curative intent. Cancer 103: 1676-1684, 2005.

26. Aaberg-Jessen C, Christensen K, Offenberg H, Bartels A, Dreehsen T, Hansen S, Schrøder HD, Brünner $\mathrm{N}$ and Kristensen BW: Low expression of tissue inhibitor of metalloproteinases-1 (TIMP-1) in glioblastoma predicts longer patient survival. J Neurooncol 95: 117-128, 2009.

27. Hayakawa T, Yamashita K, Tanzawa K, Uchijima E and Iwata K: Growth-promoting activity of tissue inhibitor of metalloproteinases-1 (TIMP-1) for a wide range of cells. A possible new growth factor in serum. FEBS Lett 298: 29-32, 1992. 
28. Alao JP: The regulation of cyclin D1 degradation: Roles in cancer development and the potential for therapeutic invention. Mol Cancer 6: 24, 2007.

29. Diehl JA: Cycling to cancer with cyclin D1. Cancer Biol Ther 1: 226-231, 2002.

30. Dworakowska D: Clinical significance of cyclin Dl expression in non-small cell lung cancer. Pneumonol Alergol Pol 73: 297-300, 2005 (In Polish).

31. Ishii Y, Pirkmaier A, Alvarez JV, Frank DA, Keselman I, Logothetis D, Mandeli J, O'Connell MJ, Waxman S and Germain D: Cyclin D1 overexpression and response to bortezomib treatment in a breast cancer model. J Natl Cancer Inst 98: 1238-1247, 2006.

32. Du WW, Yang W, Liu E, Yang Z, Dhaliwal P and Yang BB: Foxo3 circular RNA retards cell cycle progression via forming ternary complexes with p21 and CDK2. Nucleic Acids Res 44: 2846-2858, 2016.

33. Hinds PW, Mittnacht S, Dulic V, Arnold A, Reed SI and Weinberg RA: Regulation of retinoblastoma protein functions by ectopic expression of human cyclins. Cell 70: 993-1006, 1992.
34. Yam CH, Fung TK and Poon RY: Cyclin A in cell cycle control and cancer. Cell Mol Life Sci 59: 1317-1326, 2002.

35. Porta C, Paglino C and Mosca A: Targeting PI3K/Akt/mTOR Signaling in Cancer. Front Oncol 4: 64, 2014.

36. Zhang J, Yu XH, Yan YG, Wang C and Wang WJ: PI3K/Akt signaling in osteosarcoma. Clin Chim Acta 444: 182-192, 2015.

37. Dong LW, Yang GZ, Pan YF, Chen Y, Tan YX, Dai RY, Ren YB, Fu J and Wang HY: The oncoprotein p28GANK establishes a positive feedback loop in $\beta$-catenin signaling. Cell Res 21: 1248-1261, 2011.

38. Neumeister P, Pixley FJ, Xiong Y, Xie H, Wu K, Ashton A Cammer M, Chan A, Symons M, Stanley ER, et al: Cyclin D1 governs adhesion and motility of macrophages. Mol Biol Cell 14: 2005-2015, 2003.

39. Arber N, Doki Y, Han EK, Sgambato A, Zhou P, Kim NH, Delohery T, Klein MG, Holt PR and Weinstein IB: Antisense to cyclin D1 inhibits the growth and tumorigenicity of human colon cancer cells. Cancer Res 57: 1569-1574, 1997. 